Journal of Aafiyah Health Research (JAHR)

P-ISSN: 2722-4929 \& E-ISSN: 2722-4945

Published by Master Program in Public health, Muslim University of Indonesia

\title{
Dukungan Keluarga dan Keaktifan Lansia Dalam Mengikuti Program Posyandu Lansia
}

\author{
Sulistio Rini ${ }^{1}$, Endang Koni Suryaningsih* 2, Wantonoro ${ }^{3}$ \\ ${ }^{1}$ Mahasiswa DIV Bidan Pendidik, Fakultas Ilmu Kesehatan, Universitas 'Aisyiyah \\ Yogyakarta, Indonesia \\ ${ }^{2}$ Program Studi DIII Kebidanan, Fakultas Ilmu Kesehatan, Universitas 'Aisyiyah \\ Yogyakarta, Indonesia \\ ${ }^{3}$ Program Studi Keperawatan, Fakultas Ilmu Kesehatan, Universitas 'Aisyoyah \\ Yogyakarta, Indonesia \\ *Email: koni@unisayogya.ac.id
}

\begin{abstract}
ABSTRACK
Background: Aging is global phenomenom. Health aging activities program (Posyandu lansia) were developed by Indonesia goverments for maintain older person health. Family support and culture being importance factor influence of older persons in health activities program participations. The study aims to analyze the correlation between family support and elderly activeness in attending elderly health care. Methods: The correlation survey method with cross sectional approach were conducted. 114 respondents were taken using accidental sampling who met withinclusion criteria this study. Chi square statistic was used. Result: Family support to elderly activeness in attending elderly health care shows that 72 respondents support the elderly (63.2\%). Elderly activeness in attending elderly health care got 78 respondents $(68.4 \%)$ with inactive participation. There is correlation between family support and elderly activeness in attending elderly health care with $P$-value $=0.001$

Conclusion: Family support is expected to give more attention, motivation, and support to elderly, so they feel that they are still needed. Family can spare their time in reminding the schedule to attend elderly health care monthly. Family empowerment activities with older persons are recommended for future study
\end{abstract}

Keywords: family support, activeness, elderly, elderly health care 


\begin{abstract}
ABSTRAK
Latar belakang: Populasi lansia merupakan fenomena global. Posyandu lansia Indonesia dibentuk untuk mempertahankan kesehatan lansia. Budaya dan dukungan keluarga merupakan faktor yang penting dalam kegiatan posyandu lansia. Penelitian ini bertujuan untuk mengatahui hubungan antara dukungan keluarga dan keaktifan lansia dalam mengikuti kegiatan posyandu lansia. Metode: Penelitian ini menggunakan survey korelasi dengan pendekatan crosectional. 114 responden yang telah diambil menggunakan teknik accidental sampling dan mengikuti penelitian ini. Analisys statistic Chi-scuare digunakan untuk mengetahui hubungan dukungan keluarga dengan keaktifan lansia dalam mengikuti program posyandu Lansia. Hasil: sebagian besar lansia dalam penelitian ini telah mendapat dukungan dari keluarga yaitu 72 responden $(63.2 \%)$, namun terdapat sekitar $78(68,4 \%)$ responden yang tidak aktif berpartisipasi dalam kegiatan posyandu lansia. Secara statistic didapatkan hubungan yang significant antara dukungan keluarga dan keaktifan lansia dalam kegiatan posyandu lansia $(p=0.001)$. Kesimpulan: Dukungan keluarga diharapkan terus dilakukan untuk dapat memberikan perhatian, motivasi dan dukungan kepada lansia. Keluarga dapat memberikan dukungan dengan mengingatkan dan memberikan fasilitas untuk berpastisipasi dalam kegiatan setiap bulannya. Memberdayakan keluarga dalam mendukung kegiatan lansia menjadi hal yang menarik untuk peneliatian selanjutnya.
\end{abstract}

Kata kunci: dukungan keluarga, aktifitas, lansia, posyandu lansia 


\section{PENDAHULUAN}

Populasi lanjut usia (lansia) merupakan fenomena global (1). Menurut laporan United Nation (2019) telah tejadi peningkatan populasi lansia di seluruh negara di dunia, satu dari enam orang di dunia akan berusia lebih dari 65 tahun pada 2050. Laporan data demografi penduduk internasional yang dikeluarkan oleh Bureau of the Cencus USA, memprediksi bahwa Indonesia pada tahun 1990-2025 akan mempunyai kenaikan jumlah lansia tertinggi tinggi diseluruh dunia $(414 \%)$, dibandingkan dengan negara-negara lain seperti Kenya (347\%), Brazil (255\%), India (242\%), China (220\%), Jepang (129\%), Jerman (66\%) dan Swedia (33\%) (2).

Meningkatkan angka taraf hidup (life expectancy) merupakan salah satu indikasi keberhasilan pembangunan di Indonesia (3). Namun, di sisi lain dengan meningkatnya angka harapan hidup ini memberikan tantangan tersendiri bagi masyarakat dan penyedia layanan kesehatan/pemerintah, dikarenakan meningkatnya kelompok beresiko tinggi atau rentan terhadap penyakit kronik dan penurunan kapasitas fungsional karena proses penuaan dan menjadi tergantung dengan keluarga atau orang lain.

Pemerintah telah merumuskan berbagai kebijakan pelayanan kesehatan lanjut usia ditujukan untuk meningkatkan derajat kesehatan dan mutu kehidupan lansia untuk mencapai masa tua bahagia dan berdaya guna dalam kehidupan keluarga dan masyarakat sesuai dengan keberadaannya. Sebagai wujud nyata pelayanan sosial dan kesehatan pada kelompok usia lanjut, pemerintah telah merencanakan pelayanan pada lansia (Peraturan Pemerintah No. 43 tahun 2004 tentang pelaksanaan upaya peningkatan kesejahteraan sosial bagi lansia) melalui beberapa jenjang yaitu pelayanan kesehatan dasar di posyandu lansia dan puskesmas, pelayanan kesehatan tingkat lanjutan di Rumah Sakit. Dalam pelaksanaan kegiatan posyandu lansia terdapat faktor yang mempengaruhi kegiatan posyandu lansia seperti, pengetahuan lansia tentang posyandu, sikap lansia terhadap kegiatan posyandu, dan dukungan keluarga (4).

United National Population Fund, (2013) Daerah Istimewa Yogyakarta merupakan propinsi dengan life expectasy tertinggi di Indonesia yaitu sekitar 74.3. Kabupaten Sleman berpenduduk sekitar 1.180.479 jiwa (5). Demografis Kabupaten Sleman Yogyakarta berdasarkan data dari Kantor Statistik Kabupaten Sleman 2010 sebanyak 1.093.110 jiwa, dengan jumlah KK 295.181 jiwa. Dengan lansia (> 65 tahun) untuk laki-laki 30.141 jiwa dan perempuan 35.628 jiwa. Pada tahun 2015 mengalami kenaikan untuk lakilaki 54.232 jiwa dan perempuan 57.435 jiwa (6). Terdapat berbagai factor yang dapat mendukung kegiatan posyandu lansia, sepeti budaya, pengetahuan dan dukungan keluarga. Tujuan penelitian ini adalah untuk mengetahui hubungan dukungan keluarga dnegan keaktifan lansia dalam mengikuti posyandu lansia di bagian utara Sleman, Yogyakarta.

\section{METODE}

Penelitian ini menggunakan metode survey korelasional yang bertujuan untuk mengetahui korelasi antara dukungan keluarga dengan keaktifan lansia mengikuti posyandu lansia di wilayah bagian utara Sleman, Yogyakarta (No.070/Bappeda/4240/16). Pengambilan sampel dengan cara purposive sampling dengan kriteria (1) usia 60 tahun atau lebih, (2) lansia yang datang ke posyandu dan bersedia menjadi responden, (3) lansia yang tinggal bersama satu orang atau lebih 
yang masih memiliki hubungan keluarga. Terdapat 114 lansia yang bersedia menjadi responden dan mengikuti penelitian, dengan mengisi kuisioner untuk mengumpulkan data tentang dukungan keluarga yang terdiri dari 17-item dengan empat sub skala: dukungan instrumental, dukungan informasi, dukungan penghargaan, dan dukungan emosional (validity instrument cronbach alpha 0,95). Chisquare statistic digunakan untuk mengetahui hubungan dukungan keluarga dengan keaktifan lansia mengikuti posyandu lansia di wilayah bagian utara Sleman, Yogyakarta.

\section{HASIL}

\section{Analisis Univariat}

Sebagian besar lansia sangat mendapatkan dukungan dari keluarga sebanyak 72 responden (63.2\%), kurang mendukung 42 responden (36.8\%) dan tidak ada lansia yang tidak mendapat dukungan dari keluarga (gambar 1). Sebagian besar lansia tidak aktif dalam mengikuti posyandu lansia sebanyak 78 responden $(68,4 \%)$, sedangkan yang aktif dalam mengikuti posyandu lansia sebanyak 36 responden (31.6\%) (gambar 2)

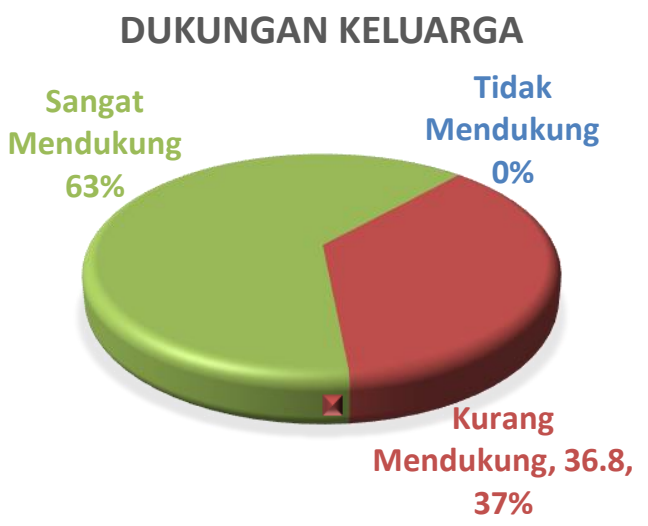

Sumber: Data Primer, 2017

Gambar 1. Diagram Distribusi Frekuensi Dukungan Keluarga Pada Lansia

\section{KEAKTIFAN LANSIA}

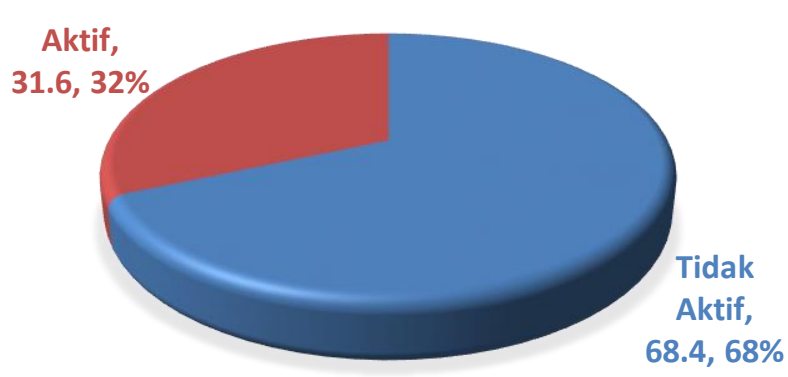

Sumber: Data Primer, 2017

Gambar 2. Diagram Distribusi Frekuensi Keaktifan Lansia Dalam Mengikut Posyandu Lansia

\section{PEMBAHASAN}

Terdapat 72 responden $(63,2 \%)$ dari 114 respondent memiliki dukungan yang baik dari keluarga untuk melakukan kegiatan di posyandu lansia. Sarafino dan Smith (2014) yang menyatakan bahwa dukungan sosial dan keluarga merupakan keberadaan, kesediaan, kepedulian dari orang-orang yang dapat diandalkan, serta menghargai dan menyayangi. Dukungan sosial merupakan bantuan atau dukungan yang positif yang diberikan oleh orang-orang tertentu terhadap individu dalam kehidupannya serta dalam lingkungan sosial tertentu sehingga individu yang menerima merasa diperhatikan, dihargai, dihormati dan dicintai. Individu yang menerima dukungan sosial akan lebih percaya diri dalam menghadapi kehidupan sehari-hari (7), termasuk untuk menguikuti kegiatan posyandu lansia. 


\section{Analisis Bivariat}

Tabel 1. Distribusi Frekuensi Antara Hubungan Dukungan Keluarga Dengan Keaktifan Lansia Dalam Mengikuti Posyandu Lansia

\begin{tabular}{|c|c|c|c|c|c|c|c|c|c|}
\hline \multirow{3}{*}{ No } & \multirow{3}{*}{$\begin{array}{l}\text { Dukungan } \\
\text { Keluarga }\end{array}$} & \multicolumn{4}{|c|}{ Keaktifan Lansia } & \multirow{2}{*}{\multicolumn{2}{|c|}{ Total }} & \multirow{3}{*}{$P$ Value* } & \multirow{3}{*}{ OR } \\
\hline & & \multicolumn{2}{|c|}{ Tidak Aktif } & \multicolumn{2}{|c|}{ Aktif } & & & & \\
\hline & & $\mathrm{F}$ & $(\%)$ & $\mathrm{F}$ & $(\%)$ & $\mathrm{F}$ & $(\%)$ & & \\
\hline 1 & $\begin{array}{l}\text { Kurang } \\
\text { Mendukung }\end{array}$ & 39 & 92.9 & 3 & 7.1 & 42 & 100.0 & & \\
\hline 2 & $\begin{array}{l}\text { Sangat } \\
\text { Mendukung }\end{array}$ & 39 & 54.2 & 33 & 45.8 & 72 & 100.0 & 0,000 & 11,000 \\
\hline & Total & 78 & 78.1 & 36 & 21.9 & 114 & 100.0 & & \\
\hline
\end{tabular}

(*) Chi Square

Hasil uji analisis (chi square) diperoleh nilai $p=0,001$

Menariknya lansia dalam kategori aktif dalam kegiatan posyandu lansia dalam peneltian ini hanya ada 36 responden $(31,6 \%)$. Hal ini perlu mendapatkan perhatian, oleh penyedia layanan kesehatan setempat dan keluarga. Keaktifan adalah suatu kesibukan yang dilakukan oleh seseorang untuk memperoleh sesuatu. Kurang aktifnya lansia dalam memanfaatkan pelayanan kesehatan di posyandu lansia, maka kondisi kesehatan mereka tidak dapat terpantau dengan baik, sehingga apabila mengalami suatu resiko penyakit akibat penurunan kondisi tubuh dan proses mengalami dikhawatirkan dapat berakibat fatal dan mengancam jiwa mereka. Maka perlunya dukungan keluarga dalam mendorong minat atau kesediaan lansia untuk mengikuti kegiatan posyandu lansia (8). Menurut Mamik (2013), keaktifan lansia datang ke Posyandu Lansia adalah suatu frekuensi keterlibatan dan keikutsertaan dalam mengikuti kegiatan posyandu secara rutin setiap bulan dan merupakan salah satu bentuk perilaku kesehatan lansia dalam upaya memelihara dan meningkatkan kesehatan dirinya secara optimal (9). Faktor penentu atau determinan perilaku manusia sulit untuk dibatasi karena perilaku merupakan kumpulan dari berbagai faktor baik internal maupun eksternal (lingkungan).

Hal ini sesuai dengan pendapat penelitian yang dilakukan Kresnawati (2013) bahwa dukungan dari keluarga (suami, istri atau anak) sangat diperlukan lansia untuk menyokong rasa percaya diri dan perasaan dapat menguasai lingkungan (10).

\section{Hubungan Dukungan Keluarga dengan Keaktifan Lansia dalam Mengikuti Posyandu Lansia}

Beradasarkan hasil penelitian ini, menginformasikan bahwa dukungan dari keluarga (family support) memiliki hubungan yang signifikan terhadap keaktifan lansia dalam mengikuti kegiatan posyandu $(\mathrm{p}=0.001)$. Dukungan keluarga sangat mendukung untuk keaktifan lansia dalam mengikuti posyandu lansia di wilayah Yogyakarta (OR: 11,000). Hasil penelitian ini 
sejalan dengan penelitian Hidawati (2016) yang menunjukkan adanya hubungan yang signifikan antara dukungan keluarga dengan keaktifan lansia dalam mengikuti kegiatan posyandu lansia (11). Dalam penelitian ini menunjukkan bahwa lansia di daerah bagian utara Sleman, Yogyakarta yang mendapatkan dukungan dari keluarga aktif mengikuti kegiatan posyandu lansia.

Dilihat dari tabel silang didapatkan lansia yang mendapat dukungan kategori sangat mendukung dari keluarga yang aktif dalam kegiatan posyandu lansia sebayak 33 responden $(45.8 \%)$. Dari hasil penelitian ini dapat di simpulkan bahwa semakin mendukung keluarga maka keaktifan lansia akan semakin meningkat. Hasil penelitian ini sejalan dengan penelitian sebelumnya (11) yang menunjukkan adanya hubungan yang signifikan antara dukungan keluarga dengan keaktifan lansia dalam mengikuti kegiatan posyandu lansia. Dalam penelitian ini menunjukkan bahwa lansia di wilayah bagian utara Sleman, Yogyakarta mendapatkan dukungan dari keluarga dan aktif mengikuti kegiatan posyandu lansia. Keaktifan lansia dalam kegiatan posyandu lansia sangat membantu petugas kesehatan dalam memantau kesehatan lansia dan memberikan pengertian tentang pola kehidupan sehat di usia lanjut. Manfaat dari keaktifan lansia di posyandu lansia untuk memudahkan petugas kesehatan dalam memperoleh data-data yang berkaitan dengan keadaan kesehatan lansia saat itu, baik vital sign dan data antopometrik serta data kondisi kesehatan terkait dengan penyakit tertentu secara berkala (8). Ginting dan Brahmana (2019) menyatakan bahwa kurangnya dukungan keluarga akan berdampak terhadapnya rendahnya partisipasi lansia dalam kegiatan posyandu (12). Gestinarwati dan Manurung (2016) menyatakan bahwa sebagian besar lansia yang active dalam posyandu merupakan lansia yang mendapatkan dukunag dari keluarga secara baik (7). Beberapa hasil penelitian lain yang mendukung hasil penelitian ini menyatakan bahwa dukungn keluarga sangat relevan dan dominan dalam memotivasi lansia untuk aktif berpartisipasid alam kegiatan posyandu lansia di wilayahnya (7,13-18). Hasil peneliataian ini memberikan gambaran bahwa dukungan keluarga merupakan faktor yang dapat dilakukan untuk dapat meningkatkan peran dan partisipasi active dari lansia dalam kegiatan posyandu lansia.

\section{Acknowledgements}

Ucapan terimakasih kami sampaikan kepada LPM Universitas 'Aisyiyah Yogyakarta dan Fakultas Ilmu Kesehatan, Universitas 'Aisyiyah Yogyakarta atas dukungan terhadap penelitian.

\section{KESIMPULAN}

Dukungan keluarga memiliki peran yang sangat signifikan bagi lansia untuk aktif berpartisipasi dalam kegiatan posyandu lansia. Diharapkan keluarga dapat memberikan perhatian, motivasi, dan dukungan kepada lansia agar lansia selalu termotivasi untuk melakukan kegiatan posyandu lansia. Pemberdayaan keluarga dalam pelaksanaan program lansia sehat menjadi hal yang menarik untuk penelitian selanjutnya. 


\section{DAFTAR PUSTAKA}

1. Notoatmojo.

Kesehatan

Masyarakat Ilmu dan Seni. Jakarta: Rineka Cipta; 2011.

2. Darmodjo, Budi. Getriatri. Jakarta: Fakultas Kedokteran Universitas Indonesia; 2011.

3. Badan Pusat Statistik Provinsi Daerah Istimewa Yogyakarta. Statistik Kesejahteraan Rakyat 2011. Provinsi Daerah Istimewa Yogyakarta; 2012.

4. Muttaqien AZ. Hubungan antara dukarga Dengan Tingkat Kepatuhan Lanjut Usia Dalam Melaksanakan Senam Lansia Diposyandu Kandang Waras Desa Ngagoejo Boyolali. J Ilm Kesehat. 2010;2.

5. Badan Pusat Statistik Provinsi Daerah Istimewa Yogyakarta. Statistik Kesejahteraan Rakyat 2015. Provinsi Daerah Istimewa Yogyakarta.; 2015.

6. Dinas kesehatan Sleman. Profil Dinas Kesehatan Kabupaten Sleman. Yogyakarta; 2015.

7. Gestinarwati A, Ilyas $\mathrm{H}$, Manurung I. Hubungan dukungan keluarga kunjungan lansia ke posyandu. J Keperawatan. 2016;XII(2):240-6.

8. Marlina N. Faktor-faktor yang berhubungan dengan keaktifan lansia di kelompok lansia "Melati B" kelurahan Abadi Jaya Di Wilayah Kerja Puskesmas Abadi Jaya Kota Depok Provinsi Jawa Barat. Universitas Indonesia;
2012.

9. Mamik E. Hubungan antara Pengetahuan dengan Keaktifan Lansia Datang ke Posyandu Lansia di Dusun Kudu Desa Kudu Banjar Kecamatan Kudu Kabupaten Jombang Tahun 2013. Skripsi. [Jombang]: STIKES Pemkab Jombang.; 2013.

10. Kresnawati I. Hubungan Dukungan Keluarga Dengan Keaktifan Lansia (Lanjut Usia) Dalam Mengikuti Kegiatan Di Posyandu Lansia Desa Gonilan Kecamatan Kartasura. J Ilm Kesehat. 2013

11. Hidawati L. Hubungan Akses Ke Posyandu, Dukungan Keluarga,Dan Keluhan Fisik Dengan Keaktifan Lansia Mengikuti Kegiatan Posyandu Puspasari Abadi V Di Gonilan Kartasura. J Ilm Kesehat. 2016;

12. Ginting D, Etalia N. Hubungan Dukungan Keluarga dengan Keaktifan Lansia Mengikuti Kegiatan Posyandu di Desa Lumban Sinaga Wilayah Kerja Puskesmas Lumban Sinaga Kecamatan Pangaribuan Kabupaten Tapanuli Utara Tahun 2017 Elderly Follows Integrated Service Post Activities in Lumb. J Healthc Technol Med. 2019;5(1):72-85.

13. Anggraini D. Faktor Dominan Lansia Aktif Mengikuti Kegiatan Posyandu di Dusun Ngentak Dominant Factors Affecting Elderly to Follow Activities. J Ners Midwifery Indones. 2015;3(3):150-5. 
14. A.A Pp, Frelestanty E, Lathifah SiN, Masan L, Noberta, Eka Y, Herman J. Dukungan keluarga terhadap keaktifan lansia dalam mengikuti posyandu lansia di puskesmas emparu. J Vokasi Kesehat [Internet]. 2017;3(2):14. Available from: http://ejournal.poltekkespontianak.ac.id/index.php/JVK\% OADUKUNGAN

15. Taman K, Kasihan T, Yogyakarta B. Hubungan dukungan emosional keluarga terhadap kunjungan lansia ke posyandu lansia di Gunung Sempu. J Phot. 2018;8(2):129-31.

16. Handayani D, Wahyuni. Kata Kunci : GASTER. 2012;9(1):4958.

17. Cahyani E. Hubungan antara dukungan keluarga dengan kunjungan lansia di posyandu lansia kelurahan Sondakan Purwosari Surakarta. Universitas Muhammadiyah Surakarta; 2018.
18. Sianturi Diana; Apriliana, Ety; Musyabiq, Sofyan; Mutiara, Utari Gita CYM. Faktor- faktor yang Berhubungan dengan Keaktifan Lanjut Usia (Lansia) Mengikuti Kegiatan Posyandu Lansia di Wilayah Puskesmas Rajabasa Indah. J Medula [Internet]. 2019;(Vol 8, No 2 (2019): Medical profesion Juornal of lampung:107-13. Available from: http://juke.kedokteran.unila.ac.id/ index.php/medula/article/view/21 79

19. United Nations, Department of Economic and Social Affairs, Population Division World Population Ageing 2019: 2019. Highlights (ST/ESA/SER.A/430).

20. United National Population Fund. Indonesian projection population BPJS-Statistic Indonesia Publication. 2013. Number: 04110.1310. ISBN: 978-979064-606-3 